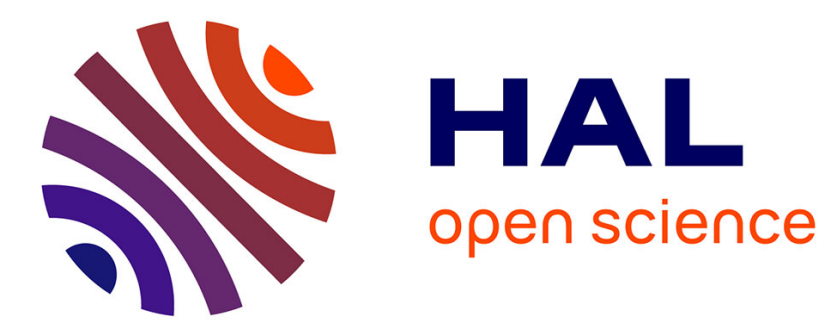

\title{
Do Women and Men Have the Same Patterns of Multiple Occupational Carcinogenic Exposures? Results from a Cohort of Cancer Patients
}

\author{
Mélanie Bertin, Annie Thébaud-Mony, Emilie Counil
}

\section{- To cite this version:}

Mélanie Bertin, Annie Thébaud-Mony, Emilie Counil. Do Women and Men Have the Same Patterns of Multiple Occupational Carcinogenic Exposures? Results from a Cohort of Cancer Patients. Annals of Work Exposures and Health, 2018, 62 (4), pp.450-464. 10.1093/annweh/wxx116 . hal-01810129

\author{
HAL Id: hal-01810129 \\ https://hal.science/hal-01810129
}

Submitted on 10 Sep 2018

HAL is a multi-disciplinary open access archive for the deposit and dissemination of scientific research documents, whether they are published or not. The documents may come from teaching and research institutions in France or abroad, or from public or private research centers.
L'archive ouverte pluridisciplinaire HAL, est destinée au dépôt et à la diffusion de documents scientifiques de niveau recherche, publiés ou non, émanant des établissements d'enseignement et de recherche français ou étrangers, des laboratoires publics ou privés. 
Do women and men have the same patterns of multiple occupational carcinogenic exposures? Results from a cohort of cancer patients

Mélanie Bertin ${ }^{1,2}$, Annie Thébaud-Mony, ${ }^{2,3}$, Emilie Couni $1^{1-4}$, the Giscop93 study group

${ }^{1}$ INSERM, U1085, IRSET, ESTER Team, University of Angers, Angers, France

${ }^{2}$ Giscop93, UFR SMBH, Paris 13 University, Bobigny, France

${ }^{3}$ UMR 8156-IRIS, UFR SMBH, Paris 13 University, Bobigny, France

${ }^{4}$ Department of Quantitative Methods in Public Health, EHESP Rennes, Sorbonne Paris

Cité, France

Correspondance to Melanie Bertin, Inserm U1085-Irset, Ester Team, University of Angers, UFR Santé - Département Médecine, 28 rue Roger Amsler, 49045 Angers, France

E-mail: melanie.bertin@univ-angers.fr 


\begin{abstract}
Complex exposure situations are frequent at the workplace, but few studies have characterized multiple occupational carcinogenic exposures (MOCE) and their gendered differences across jobs' characteristics. We assessed MOCE separately in male and female jobs, and identified patterns of MOCE at job level.

Participants (834 men and 183 women) were cancer patients recruited between March 2002 and December 2010 in the ongoing SCOP93 cohort study, Seine-Saint-Denis department, France. Job histories were collected through personal interviews and carcinogenic exposures were assessed by a multidisciplinary expert committee using a list of 53 carcinogens. Proportion of MOCE (i.e. $\geq 2$ carcinogens) was assessed for male and female jobs separately. Principal Component Analysis combined with Hierarchical Ascendant Classification was used to identify patterns of MOCE.
\end{abstract}

Among the 5,202 male jobs and 885 female jobs, respectively 42\% and 9\% were multiexposed. Blue-collar workers and jobs in the construction and industry sectors had the highest rates of MOCE, contrasting with jobs held in recent periods $(\geq 1997)$ and by patients aged $\geq 45$ $\mathrm{y} / \mathrm{o}$ at job start. A gradient of MOCE was also observed according to occupational segregation for both men and women. Eight patterns of MOCE were identified among male jobs: widespread carcinogens, mixed silica dust, heavy metals/combustion products, organic compounds/radiation, metal working, solvents/heavy metals, wood dust/formaldehyde/pesticides, and fuel exhausts. Three patterns of MOCE were found among female jobs: biological/organic compounds, industrial working, and fuel exhausts. Some patterns of MOCE were job-specific, while other patterns were found across different occupations.

These results suggest that patterns of MOCE partly differ between men and women. They stress the importance of gendering multiple exposure assessment studies and point out the inadequacy of occupational disease compensation systems based on a single factor and nongendered approach of carcinogenesis, ignoring differences between men and women in complex occupational exposure situations.

\title{
Keywords
}

Occupational carcinogen; multiple exposures; gender; patterns; cancer 


\section{Introduction}

While thousands of chemicals are used over the world without any proper testing, a small fraction has at least partially been evaluated for carcinogenicity. The International Agency for Research on Cancer (IARC) has classified around 230 agents found in the workplace as carcinogenic to humans (group 1, $\mathrm{n}=65$ ), probably carcinogenic (group 2A, $\mathrm{n}=45$ ) or possibly carcinogenic to humans (group 2B, n=120) (International Agency for Research on Cancer, 2017). However, despite this well-established classification, the monitoring of occupational exposures to known carcinogens is too often lacking at a national level. This knowledge gap has repeatedly been pointed out as a major limitation to both the prevention of occupational cancer (Kauppinen et al., 2000; Hall et al., 2014) and the assessment of the burden of workrelated cancer, which may be considered as a "strategic step” to prevention (Straif, 2012).

Notable exceptions do exist, starting with the CAREX (CARcinogen EXposure) initiative in Europe, which has produced national estimates of the number of workers exposed to 85 agents over the 1990-93 period in 15 EU countries, with distribution by carcinogen and industry sectors (Kauppinen et al., 2000). A CAREX-Canada initiative followed, which provided estimates for 44 carcinogens in 2006 (Peters et al., 2015). In France, the periodic and national SUMER (“Surveillance médicale des risques professionnels”) survey was set in 1987. In 2010, 24 chemical carcinogens were assessed, plus ionizing radiation and night work for women (Fréry et al., 2016). Such studies or surveillance systems usually report estimates of prevalence of exposure by carcinogen or the prevalence of exposure to at least one carcinogen among those listed. Yet, the real working life experience of many blue collar workers has been and - for some - remains that of multiple exposures encountered repeatedly across different types of jobs, activity sectors and periods (RESEAU SCOP93, 2005). Methodologically, multiple exposures make it difficult to isolate the effect of a single exposure on health, as most of epidemiological studies try to do (Momoli et al. 2010). Documenting real working life situations of MOCE might help moving from the risk factor paradigm to the study of combined effects of specific exposure profiles (Papathomas et al., 2011). This is in line with the rising attention given to "exposome" and its potential relevance for reflecting workplace exposures (Siemiatycki et al., 2004; Wild, 2005). This concept also raises other concerns, including the assessment of both the carcinogenic potential of low-dose exposures to chemical mixtures (Goodson et al., 2015) and the dose-additive carcinogenicity of mixtures (Walker et al., 2004). This is, of course, of particular importance not only in terms of hazard identification and risk assessment, but also when it comes to target interventions to 
prevent occupational cancer at the workplace. As the knowledge gap is even deeper when it comes to documenting typical co-occurrence of carcinogenic agents linked to specific positions, tasks, side activities and work and/or site organization, there is a special need to explore real working life patterns of MOCE in relation to specific locations of cancer (Faisandier et al., 2011).

Another striking feature of the (M)OCE knowledge gap is the deficit of exposures documented among female compared to male workers. Many studies have been conducted in men only, based on the strong belief that women's work was generally safer (Messing, 1998). When mixed studies have been reported, including results stratified on sex, OCE have systematically been far higher in men, with few exceptions such as antineoplastic agents, hair dyes, textile dust or shift work (EU-OSHA, 2014). In France, the estimated prevalence of MOCE among men was 6 times higher than among women in 2010 (6\% versus 1\% exposed to multiple occupational carcinogens, based on a selection of 24 chemical carcinogens assessed, ionizing radiation, and night work for women) (Fréry et al., 2016). Substantial gendered differences in occupational exposures (not only to carcinogens) have been shown between and within occupations, raising interpretation issues about the extent to which such differences between men and women would be due to differences in jobs held, differences in tasks performed within the same job, and/or differences in self-report (where applicable) (Quinn, 2011). As previously pointed out by Kennedy \& Koehoorn (2003), the scope of gender differences in OCE and MOCE at the job level still needs to be evaluated if we want to understand gender differences in occupational morbidity. Yet, we need more gender-sensitive approaches of exposure assessment if we want to avoid differential information bias among women as compared to men (Vogel, 2003). Observations that men and women matched on occupation still may experience different exposures should warn us against the use of job titles as surrogates for exposure assessment (Eng et al., 2011).

Our study aimed at evaluating the prevalence of OCE and MOCE at the job level, separately for men and women suffering from lung, urinary tract and hematological cancer, and then identifying patterns of MOCE among jobs held by men compared to women.

It is based on an interdisciplinary action-research program (RESEAU SCOP93, 2005) which developed a gender-sensitive approach to retrospective exposure assessment, firstly by expanding and adapting the list of known or suspected occupational carcinogens to better match women's exposure situations and secondly by collecting detailed description of realwork activities and using expert judgment rather than directly questioning workers about their exposures. 


\section{Methods}

\section{Study population}

This study is based on a cohort of cancer patients conducted by the Giscop93 (Groupement d'Intérêt Scientifique sur les Cancers d'Origine Professionnelle), a scientific network exploring work-related cancer in Seine-Saint-Denis (SSD). SSD is a French district (number 93) with strong industrial past and presently a lot of suppliers in metallurgy and construction sectors. SSD has experienced excess mortality rate by cancer in both men and women since the 1980's. The detailed survey methodology has been previously described (RESEAU SCOP93, 2005). The present analysis includes data from histologically confirmed incident cancer cases for patients suffering from primary tumors of the respiratory or urinary tract, more rarely leukemia, and that was collected in specialized services of three public SSD hospitals from March 2002 to December 2010.

Each subject gave written informed consent. The study was approved by the Institutional Review Board of the French National Institute of Health and Medical Research (no 10.672), and by the French Data Protection Authority (CNIL no. 911121).

\section{Collection and coding of medical information and patients' occupational histories}

Information on the date and type of diagnosis, histologic confirmation and staging of cancer were retrieved from hospital medical records. Job histories were instead collected from the patients by sociologists, with a focus on activity at each job held over the occupational life course (Thébaud-Mony, 2006; Lanna, 2013). In this approach, the patients are interviewed as experts of their own work, not of their exposures; they are thus asked to describe their realwork activity in terms of various tasks performed, including process, equipment and chemicals used/handled; also, tasks performed by co-workers and nearby processes to assess the possibility of indirect exposures. Job periods were coded using the 4-digit code of the French Classification of Occupations - Professions et catégories socioprofessionnelles (PCS) , while industry sectors (of employers) were coded using the 4-digit French classification for economic activities - Nomenclature des Activités Françaises (NAF). NAF is a slightly more detailed version of the European classification (NACE). 
Assessment of occupational exposures to known or suspected carcinogens

Detailed job descriptions were submitted to a multidisciplinary expert committee blind to the exact diagnosis (stage and tumor site). Experts assessed the characteristics of OCE in terms of substance/agent, probability of occurrence (3 categories), intensity (5 categories), frequency (4 categories), peaks (yes/no) and duration (years or months). They checked OCE against a list of 53 agents (or group of agents) recognized as either “certainly," "probably”, or "possibly" carcinogenic by the European Union and/or the International Agency for Research on Cancer (IARC) (Table S1). That list was susceptible to be amended following the evolution of IARC and/or UE classification and relevance for the expertise.

\section{Statistical analyses}

- Data handling and descriptive analyses

The variables included to describe the study population were: sex, age at diagnosis, cancer location, metastasis, the year of career's start, main activity sector, number of jobs held and number of occupational carcinogens encountered over the career. The variables used to assess jobs' characteristics were: occupational category, activity sector, period and age at job start and sex segregation. For the purpose of this study, detailed occupational categories were grouped into 13 groups: 1) professionals and managers, 2) associate professionals, 3) services, sales and administration workers, 4) technicians, 5) agricultural, fish and forestry workers, 6) drivers, transport and supply chain workers, 7) construction workers, 8) electrical and electronic trades workers, 9) wood, confection and printing workers, 10) metal and mechanical workers, 11) industrial processing workers, 12) other workers (including workers in butchery, bakery, as kitchen assistants; cleaners and other workers whose jobs were not clearly identified), and 13) army. Industry sectors were also grouped as: 1) agriculture, fishing and forestry, 2) construction, 3) services, 4) industry . Occupational (sex) segregation was based on 1983 national data (Argouarc'h and Calavrezo, 2013) and defined following Hakim (Hakim, 1993) as: men-dominated occupations where the proportion of women is lower than the average across all occupations minus $15 \%$ e.g. proportion of women $<26.7 \%$; womendominated occupations where the proportion of women in the occupation is higher than the average across all occupations plus $15 \%$ e.g. proportion of women $>56.7 \%$; and mixed occupations where the proportion of women lies between 26.7 and 56.7\%. 
Description of study population and jobs' characteristics were performed by gender. Due to potential low number of observations, the Fisher exact test (with alpha $=5 \%$ ) was used to compare between men and women participants as well as their relative jobs characteristics

- Identification of MOCE patterns at the job level.

Jobs were considered as multi-exposed to OCE if the experts had rated at least two carcinogens of the list as having a non-zero probability (rescaled from 0.1 to 1.0) of occurrence during this specific job. Because our aim was to estimate main co-occurrences of OCE, the probability criterion was the fitted predictor to identify patterns of MOCE whatever their associated frequency, intensity, duration or peaks. MOCE patterns were identified separately in male and female multi-exposed jobs by using a two-step method that consisted in using Principal Component Analysis (PCA) as a pre-processing step before performing the clustering method, which provided more statistical stability and robustness to the clustering process, thus minimizing the risk of individual misclassification (Ben-Hur and Guyon, 2003; Husson et al., 2010). Briefly, the 53 variables - assessing the probability of exposure to the 53 carcinogens - were first combined into a smaller number of uncorrelated factors called principal components that account for most of the variance in the initial 53 variables. The positions of each observation (i.e. multi-exposed jobs) in this new coordinate system of principal components are called scores. The latter were then used as input to the clustering procedure, a Hierarchical Ascendant Classification (HAC) based on the Euclidean distance between observations and Ward's algorithm (Lebart et al., 2000). The v-test parameter (See definition and formula in supplementary materials) was used for MOCE patterns interpretation. Carcinogens associated with a positive and significant v-test (with $\alpha=5 \%$ ) were retained for the patterns’ interpretation (Tables S2 and S3).

\section{- Occupational diversity index}

An occupational diversity index (ODI) was developed based on the Shannon entropy formula to assess the heterogeneity of occupational categories among each MOCE pattern (Martin, 2000). The Shannon entropy was estimated by using the 4-digit code of the French classification of occupations (PCS) distribution among each pattern of MOCE identified in male or female jobs. A pattern associated with low entropy (closer to 0 ) is mainly composed of homogeneous occupational categories (i.e. occupation/job-specific MOCE pattern) while a high entropy (closer to 1) suggests a MOCE pattern that is observed among heterogeneous occupational categories/jobs. 
Descriptive analysis and MOCE patterns' elaboration were performed with STATA SE version 14 (College Station, TX, StataCorp LP). ODI was elaborated by coding the Shannon entropy function in R software.

\section{Results}

\section{Study population characteristics}

Table 1 presents the medical and sociodemographic characteristics of the 1,017 cancer patients (834 men and 183 women) included in the analyses. Participants (both men and women) were mostly diagnosed with respiratory tract cancer $(94 \%, \mathrm{p}=0.20)$ at an advanced stage of their disease ( $45 \%$ had metastasis, $\mathrm{p}=0.96$ ). However, men included in the cohort were older at time of diagnosis as compared to women $(\mathrm{p}<0.001)$ and accordingly women started their career later in the 20th century $(\mathrm{p}<0.001)$. Men held a higher number of jobs $(6.3$ vs. 4.9 for women $\mathrm{p}<0.001)$ and were on average exposed to more occupational carcinogens (6.3 min-max: 0-12 vs. 1.4 min-max: 0-7 for women, $\mathrm{p}<0.001$ ) during their career.

\section{Job characteristics}

Table 2 presents the jobs' characteristics of men and women. Occupational histories of patients included a total of 5,202 jobs held by men and 885 jobs held by women. Characteristics of jobs differed depending on participants' gender. While more than half of the men's and women's jobs were in the manufacturing and extractive industry sector, other men's jobs distributed equally between the construction sector (23.9\%) and services (21.5\%), whereas most of the remaining jobs held by women corresponded to services activities (46.1\%), $\mathrm{p}<0.001$. Among blue-collar men’s jobs, metal and mechanical industrial jobs were particularly frequent (19.0\%) while industrial processing jobs represented $8.7 \%$ of jobs held by women $(\mathrm{p}<0.001)$. Finally, jobs recorded from women more often started in the 1970s and thereafter (64.2\%), as compared to those recorded from men $(49.4 \%, \mathrm{p}<0.001)$. Occupational segregation was observed ( $<<0.001$ ), with $63.1 \%$ of jobs held by men considered as mendominated occupations and $58.7 \%$ of jobs held by women considered as women-dominated occupations.

\section{Occupational carcinogenic exposures and multiple exposures}

The five most prevalent carcinogens found in men's jobs were asbestos, silica, PAHs (Polycyclic aromatic hydrocarbons), chlorinated solvents, and welding fumes, while in jobs 
held by women, asbestos, passive smoking, chlorinated solvents, formaldehyde and PAHs were the most prevalent ones (Table S1).

Table 3 presents the results of OCE and MOCE by gender and job characteristics. Occupational exposure to at least one carcinogen was frequent among both men and women, but higher proportions were observed among jobs held by men (61.1\% vs $26.7 \%, \mathrm{p}<0.001)$. The gender gap was even more pronounced for MOCE, which was observed in $41.8 \%$ of jobs held by men (2,173 jobs) and 9.3\% of jobs held by women (82 jobs, $\mathrm{p}<0.001)$.

Among men's jobs, those in the construction were the most frequently exposed and multiexposed jobs (89.9\% and 64.2\%, respectively), together with metal and mechanical workers (88.1\% and 70.0\% respectively), but many other occupations were found to be multi-exposed, such as wood, confection and printing workers (48.0\%), technicians (41.4\%) and electrical and electronic trades workers (38.0\%). The lowest proportions of MOCE were found among professionals and managers (8.1\%), services, sales and administration workers (8.4\%) and army (9.8\%). MOCE were also particularly observed among men's jobs that started during the 1950-1969 period (44.9\% of MOCE) and remained high among jobs starting between 1970 and 1995 (41.2\%), but were already reported for jobs which started before 1950 (38.1\%). They substantially decreased in men's jobs which started after 1997, but remained high $(27.2 \%, \mathrm{p}<0.001)$.

Among women's jobs, higher proportions of MOCE were found among metal and mechanical workers (41.3\%), followed by far by electrical and electronic trades workers (18.2\%), wood, confection and printing workers (16.7\%), the group of “other workers” (13.0\%) and industrial processing workers (9.1\%). Lower occurrence of MOCE was reported for women's jobs starting after 1997 (e.g. 4.4\%), yet the time trend was not significant $(\mathrm{p}=0.187)$.

Interestingly, whatever the sex of patient, a significant gradient was observed for both OCE and MOCE depending on occupational (sex) segregation (Table 3). MOCE reached $54.8 \%$ in jobs held by men classified as “men-dominated occupations”, 26.6\% in “mixed occupations”, and $8.5 \%$ in "women-dominated occupations" $(\mathrm{p}<0.001)$. In jobs held by women, these figures, though lower, respectively reached $24.2 \%, 11.0 \%$ and $5.8 \%(\mathrm{p}<0.001)$.

\section{MOCE patterns}

MOCE patterns were defined for men's and women's jobs separately and are described in Table 4. These patterns were labeled based on the most representative carcinogens of each 
cluster (Table S2-S3) and described following the distribution of sectors and occupations (Figure 1, Table S4-S5 and Figure S1).

Among multi-exposed jobs recorded in men $(n=2173)$, nine principal components were retained after PCA, which explained 35.3\% of the total inertia. Each individual score on these nine principal components were directly inputted in the HAC, from which 8 clusters were identified corresponding to 8 patterns of MOCE. The first pattern named "widespread carcinogens” ( $\mathrm{n}=548,25.2 \%)$ was particularly observed among construction and metal and mechanical jobs but a wide spectrum of occupational sectors and categories were also associated with such pattern (occupational diversity index, ODI=0.60). The "mixed silica dust” pattern ( $n=401,18.5 \%)$ was mostly observed among men's jobs in the construction sector $(\mathrm{ODI}=0.37)$. The third pattern $(\mathrm{n}=64,2.9 \%)$ characterized by numerous "heavy metals and combustion products" included a more limited type of men's jobs (ODI=0.17) specifically exposed to such substances. The fourth pattern ( $n=90,4.1 \%)$ included jobs mostly exposed to "organic compounds and radiation" which covered jobs spanning from the metallurgy to those in the car industry or maintenance (mechanics and electro-mechanics) (ODI=0.27). The "metal working” pattern ( $n=532,24.5 \%)$ mainly gathered jobs from the metal and mechanical industry or others that shares common exposures to the work or use of such materials found in many types of jobs (ODI=0.61). The sixth pattern $(n=139,6.4 \%)$ characterized by the association of "solvents and painting related compounds" - concerned mostly painters and renderers from the construction sector or from the manufacturing industry (car or printing) but also activities that required the manipulation and work of painted surfaces (ODI=0.07). The “wood dust, formaldehyde and pesticides” pattern $(n=226,10.4 \%)$ was typically associated with jobs either in the manufacturing and extractive industry, construction based on woodworking or wood processing (ODI=0.42), and included $88 \%$ of the jobs in agriculture (Table S4). Finally, the last pattern included men's jobs exposed to "fuels exhausts" ( $n=173,8.0 \%)$ that were mainly jobs of drivers or jobs in transport and supply chains (ODI=0.31).

Among multi-exposed jobs recorded in women $(n=82)$, eight principal components were retained after the PCA, which explained $64.1 \%$ of the total variability. Three clusters were identified from the HAC based on those eight principal components, corresponding to three MOCE patterns. The first pattern ( $n=48,58.5 \%)$ was characterized by women's jobs exposed conjointly to "passive smoking, and biological or organic compounds". It included a diversity of occupations that stretched from the manufacturing and extractive industry to services 
sectors (ODI=0.49). The “industrial work” pattern ( $\mathrm{n}=26,31.7 \%)$ concerned mostly women's jobs as blue-collar workers among which 53\% came from the metal and mechanical industry (ODI=0.35). The last pattern concerned the few jobs $(n=8,9.8 \%$; ODI=0.15) with MOCE to "fuel exhausts" mainly in the services sector which suggest that contrary to the "fuel exhausts” pattern in men's jobs, the exposure was mostly indirect, due to the workplace environment (i.e. not due to the tasks performed). As shown in Figure 2, while mendominated occupations represented only $26.8 \%$ of multiply-exposed jobs among women, they were over-represented in the "industrial work" pattern (53.9\%) and under-represented in the "passive smoking, and biological or organic compounds" pattern (12.5\%), indicating specificities in MOCE patterns encountered by women depending on occupational segregation.

\section{Discussion}

This study based on a French case-only cohort highlights proportions and situations of MOCE at job level among both men and women cancer patients with mostly lung cancer. It suggests different patterns of MOCE patterns by gender.

Firstly, The specificities, and also somehow the strengths of this study, lie in the hospitalbased approach that allowed the tracing of (M)OCE backwards from cancer patients diagnosed in the oncology services of public hospitals. This is more likely to uncover various exposure situations as in France patients are referred to consultations specialized in occupational medicine only once a GP or specialist first suspects a link with occupation; a role for which they receive barely any formal training, apart from very few and typical exposure-cancer combinations. In our study, cancer is thus considered a so-called "sentinel event” to uncover such potentially unrecognized situations of former occupational exposures to carcinogens in a French district known for its intense industrial past and its actual labor market based on supply chains in manufacturing, construction and services. Our study population was therefore tailored towards blue-collar occupations greater exposed to carcinogens, in relation to the increasing flexibility in employment, as well as the social division of labor and hazards over the last thirty years (RESEAU SCOP93, 2005). Second, the multidisciplinary expertise of OCE based on the reconstruction of jobs' histories by sociologists led to the provision of an enlarged vision of MOCE. The wide list of occupational carcinogens fits the progression of scientific knowledge about carcinogenicity and trends in the labor market across the different periods covered by patients' jobs histories. It notably 
includes carcinogens particularly relevant for women. Finally, MOCE patterns were elaborated based on the probabilities of exposure of the job to each carcinogen, allowing identification of realistic multiple exposure patterns.

Nevertheless, this interesting and innovating study design has its own inherent limits. The cancer case-only cohort developed in collaboration with 3 to 4 SSD hospitals was not representative of the French working population. Nevertheless, a comparative qualitative study between Giscop93 patients and healthy workers who have been identified as exposed in the SUMER study 2003 (same age, same qualification, same economic sector) did not show differences in relation to exposed job histories (Thébaud-Mony and Daubas-Letourneux, 2009). The industrial past of SSD (e.g. predominance of construction workers and metal and mechanical workers) has also probably driven the type of MOCE patterns identified. Yet, the present structure of the labor market is concentrating chemical hazards in workers with the most precarious status and working conditions (Thébaud-Mony, 2006; Counil, 2015). Although we believe the collection and coding of job histories by trained sociologists of work and industry allowed informed choices about the most appropriate coding of occupations based on each specific real-work situation, it may have introduced some variability in the coding of occupations at the finest level (e.g. 4-digit), while most of the present analysis was based on 2 digits, except for the calculation of the OCI. Also, to avoid complex interpretation of classifications based on multidimensional scores (e.g. such as probability*intensity*frequency*duration), only the probability criterion for exposure assessment was used to weigh each carcinogenic agent in the analytic procedure to identify MOCE patterns. Furthermore, the cancer site specificity was not taken into account in our analysis (i.e. all carcinogens were considered, without grouping those for which the level of evidence is strong for different locations, starting with lung). Finally, a low proportion of women (18\%) was included in this cohort, mainly due to the recruitment process (mostly lung cancer cases, with a man to woman ratio of 6.1 in the year 2000 in France-Molinié et al., 2006) but maybe also due to self-selection based on the scope of the study (occupational cancer, which is considered socially as more frequent among men). The limited number of participating women certainly explains the lower diversity in MOCE patterns observed (3 MOCE patterns among jobs held by women versus 8 among jobs held by men). However, stratifying our sample on the sex of the patient who held the job conversely allowed us to identify a pattern specific to women's jobs (e.g. the "biological and organic compounds" pattern). 
Our findings suggest that a high proportion of jobs were multi-exposed to carcinogens. Jobs held by men were more frequently multi-exposed to OCE (42\%), as well as men-dominated occupations, both among jobs held by men and women, though to a lesser extent in the later (55\% vs. 24\%). Yet, circa 10\% of women's jobs were exposed to at least two carcinogens, and MOCE was reported for respectively $9 \%$ and $6 \%$ of jobs held by men and women in women-dominated occupations. It is interesting to note that however imprecise the definition of sex segregation might be in our study, with the women-dominated group including occupations with up to $43 \%$ of men, the gradient of (M)OCE was consistent across genders. In the French representative and cross-sectional SUMER 2010 survey, the prevalence of MOCE observed was much lower: almost $6 \%$ of men and $1 \%$ of women were exposed to multiple occupational carcinogens (Fréry et al., 2016). This large difference between the two studies may be explained by different factors. First, the proportion of blue-collar jobs is high in the Giscop93 cohort (72\% of men's jobs and 34\% of women's jobs), while they represent only 29\% of the 2010 French active population (43\% of men's jobs and 11\% of women's jobs). This occupational concentration is reinforced among men who often worked in the construction sector. Second, only 24 occupational carcinogens were assessed in the SUMER 2010 survey, while at least 53 carcinogens (with an extra open-ended category) were considered in the Giscop93 multidisciplinary expertise. Third, many of the Giscop93 patients worked during a significant part of their career in SSD, a district known for its particular tissue of small and medium-sized enterprises, where (M)OCE are more frequent (Cavet \& Léonard, 2013). Lastly, OCE were assessed across the full job histories in the Giscop93 cohort (spanning from 1922 to 2010). We observed that OCE and MOCE tended to decrease in the recent periods, particularly after 1997, the year of the asbestos ban in France. This result highlights the beneficial impact of the asbestos ban for occupational exposures prevention and safety at work.

OCE was also shown to decrease with age at job start, especially among male workers older than 45 years-old. The reasons which might account for this finding are complex: better occupational health and safety as well as prevention, upward occupational trajectories that could lead to more qualified and less exposed jobs, but also the fact that the division of work and hazards is concentrating exposure in the most precarious and less qualified workers, who are basically young people.

MOCE were mostly observed among the most disadvantaged occupational categories which confirms that working conditions may highly contribute to social health inequalities 
(Niedhammer et al., 2008). Jobs held by both male and female workers from either the metal and mechanical industry, wood industry or processing industry were highly exposed to carcinogens. Interestingly, though to a lesser extent, men's and women's jobs in the services, sales and administration were also exposed to OCE (respectively $22.4 \%$ and $20.0 \%$ of jobs) which emphasizes the ubiquity of OCE. We also found that men in the construction sector were highly exposed to multiple carcinogens.

Furthermore, among both men's and women's jobs, a gradient of (M)OCE according to occupational segregation was found, men-dominated occupations being the most exposed. This result suggests that beyond the social etiology of MOCE, gender also matters. As previously suggested, there is a high degree of heterogeneity in OCE by gender, partly due to the specific places occupied by men and women on the labor market (Eng et al., 2011; Quinn, 2011). Eight patterns of MOCE were found among jobs held by men while only three patterns were identified among jobs held by women. Co-occurrences of occupational carcinogenic exposures were therefore mostly gendered. For example, the 'mixed silica dust' pattern was exclusively found among jobs held by men which corroborated with the men-oriented construction sector (only 14 jobs held by women) mainly represented in this MOCE pattern (76\% of jobs). The 'fuel exhausts' pattern was found in both men's and women's jobs, underlining the systematic co-occurrence of the two carcinogenic agents (gasoline and diesel exhausts), even if associated to very different exposure situations. While exposures in men's jobs were mainly due to their jobs' tasks (drivers, car mechanic or technician...), in women's jobs they were mostly induced by their work environment (i.e. secretaries working in a garage). This distinction between work task and work environment related exposures partly explained the heterogeneity of occupations in the MOCE patterns identified. Similarly, the inspection of the distribution of occupational categories by MOCE patterns showed that some patterns were job/occupation specific, such as "wood dust, formaldehyde and pesticides" including $87.5 \%$ of the agricultural jobs, or the "fuel exhausts" pattern including $67 \%$ of drivers, transport or supply chain workers (Table S4). Conversely, other occupational categories were equally distributed among different patterns, particularly among men’s jobs. Industrial processing workers could for instance be associated with diverse exposure profiles corresponding to each of the 8 patterns, though to a different extent, in particular "metal working”, “wood dust, formaldehyde and pesticides” and "solvents and heavy metals”.

The identification of MOCE patterns also confirmed the recurrence of two or more concomitant carcinogens across different types of jobs, stressing the need to assess the 
prevalence of MOCE and their potential effects on health. Occupational exposures used to be studied separately from one another. However, many workers are simultaneously exposed to various hazards (Wild, 2005). And yet, studies exploring MOCE are still lacking. A better knowledge of multiple occupational exposures, and in particular to carcinogens, is necessary in order to improve occupational risks assessment and prevention at the workplace. It is a necessary step in the risk prevention process, in order to preserve health and safety at work and to inform public policies. Following that challenge, the Giscop93 cohort, tracing occupational exposures backwards from cancer patients, is a very important and interesting retrospective approach to identifying carcinogens which, though regulated, are still present in workplaces and generate multiple exposures among most disadvantaged occupational categories. It therefore provides a clear logic to understand how cancer can be prevented through the elimination of carcinogenic exposures (Takala, 2015). Furthermore, the prospective phase of the Giscop93 cohort that follows patients during the notification and compensation procedure, points out the inadequacy of the occupational disease compensation systems based on a single factor and non-gendered approach of carcinogenesis, ignoring differences between men and women in complex occupational exposure situations (Marchand, 2016).

\section{Conclusion}

Occupational exposures are of particular interest for cancer prevention, as workers usually have low latitude in avoiding them and they are of greater magnitude than those encountered in the general environment. The growing use of minerals, chemicals and radioactive sources after World War II, together with the changes in work organization and social division of occupational risks from the 1970s, progressively challenged the simplistic vision of a bluecollar man, holding over the years the same job in the same company, where he would be heavily and directly exposed to a single agent or a stable set of agents, which health consequences could be monitored through meticulous follow-up or retrospective cohorts. This model, in addition to prevailing in many occupational cancer epidemiology studies over decades, presently dominates many occupational disease compensation systems, notably the French compensation system. This system is based on a limited number of "single agent tumor site" combinations, usually defined based on traditionally working situations in male workers, and the necessity for workers to provide evidence of significant if not massive exposure to one of the listed agents (if any) compatible with their disease status. 
Our results based on a case-only cohort and using a gender-sensitive approach of exposure assessment suggest that multiple OCE has occurred regularly among the most disadvantaged occupational categories, and more frequently among men than among women. Beyond OCE differences by gender, they also describe patterns of MOCE that partly differ between men and women, but also according to the level of occupational segregation. They stress the importance of conducting multiple exposure assessment studies which account for gendered differences. More broadly, they point the inadequacy of occupational disease compensation systems that are based on a single factor and non-gendered approach of carcinogenesis. To avoid "one-eyed science" (Messing, 1998) and the related unequal prevention and compensation of occupational cancer between men and women, the degree of heterogeneity in OCE by gender should also be taken into account. 


\section{Funding}

This work was supported by a grant from the French Institute of Cancer (Inca), Contract no. APR-SHS-ESP-2010 (ECART project). The Giscop93 permanent study is funded by CG93 (Seine-Saint-Denis department), DGT (French Ministry of Labour), Ligue départementale de lutte contre le cancer du 93 and Cpam93 (Seine-Saint-Denis General regime of Health insurance).

\section{Acknowledgments}

All participating hospitals, physicists, patients and families, and the expert committee.

\section{Collaborators}

\section{The Giscop93 study group :}

The Giscop93 team : Annie Thébaud-Mony, Parvine Badouraly, Laura Boujasson, Darioush Chi, Catherine Lepetit, Michaël Levy, Valérie Grassulo, Michèle Vincenti, Flavienne Lanna, Michelle Paiva, Valérie, Anne-Claire Brisasier, Sylvie Platel, Anne Marchand, Benjamin Lysaniuk, Christophe Coutanceau, Maxime Quijoux, Magali Turquis, Véronique DaubasLetourneux, Emilie Counil, Mélanie Bertin.

The Giscop93 expertise committee : Michel Héry, Jean-Michel Sterdyniak, Alain Bobbio, Jean-Claude Bodart, Frank Bernard, Pierre Cousaut, Yvon Creau, Hélène Hasni-Pichard, Marie-Ange André-Lesage Michel GOUDAL, Thierry Viallesoubranne, Philippe Davezies, Michel Goudal, Isabelle Badinier, Alain Remoiville.

\section{Contributions}

MB and EC conceived the study, designed the statistical analytic approach, analyzed and interpreted the data and wrote the manuscript. ATM. designed the SCOP93 cohort and provides extensive feedback on patterns' interpretation. The Giscop93 team contributed to the data collection and entry and the expert committee assessed occupational carcinogenic exposures. All the authors critically revised and approved the final manuscript submitted for publication. The authors report no conflict of interest. 


\section{References}

Argouarc’h J, Calavrezo O. (2013) La répartition des hommes et des femmes par métiers : Une baisse de la ségrégation depuis 30 ans. Dares Analyses; 79. http://dares.travailemploi.gouv.fr/IMG/pdf/2013-079.pdf (Accessed June 12, 2017)

Ben-Hur A, Guyon I. (2003) Detecting Stable Clusters Using Principal Component Analysis. Funct Genomics Methods Protoc; 224:159-82.

Cavet M, Léonard M. (2013) Les expositions aux produits chimiques cancérogènes en 2010. Dares Analyses 54:1-9. http://dares.travail-emploi.gouv.fr/IMG/pdf/2015-074.pdf (Accessed June 12, 2017)

Counil E. (2015) Inégalités des parcours de travail et histoires d'exposition aux cancérogènes. In Les Risques du travail. Pour ne pas perdre sa vie à la gagner. Paris: La Découverte. p. 124-128. ISBN 9782707178404

Eng A, 't Mannetje A, McLean D, Ellison-Loschmann L, Cheng S, Pearce N. (2011) Gender differences in occupational exposure patterns. Occup Environ Med; 68:888-94.

EU-OSHA (2014) Exposure to carcinogens and work-related cancer: A review of assessment measures. Luxembourg: European Agency for Safety and Health at Work. https://osha.europa.eu/fr/tools-and-publications/publications/reports/report-soar-work-related-cancer (Accessed June 12, 2017)

Faisandier L, Bonneterre V, De Gaudemaris R, Bicout DJ. (2011) Occupational exposome: A network-based approach for characterizing Occupational Health Problems. J Biomed Inform; 44:545552.

Fréry N, Moisan F, Schwaab Y, Garnier R. (2016) Multi-expositions professionnelles à des agents cancérogènes chez les salariés en 2010. Saint-Maurice : Santé Publique France. 16 p.

Goodson WH, Lowe L, Carpenter DO, Gilbertson M, Manaf Ali A, Lopez de Cerain Salsamendi A, et al. (2015) Assessing the carcinogenic potential of low-dose exposures to chemical mixtures in the environment: the challenge ahead. Carcinogenesis; 36:S254-96.

Hakim C. (1993) Segregated and Integrated Occupations: A New Approach to Analysing Social Change. Eur Sociol Rev; 9:289-314.

Hall A, Peters C, Demers P, Davies H. (2014) Exposed! Or not? The diminishing record of workplace exposure in Canada. Can J Public Heal; 105:214-217. 
Husson F, Le S, Pages J. (2010) Clustering and Principal Component Methods. In: Exploratory Multivariate Analysis by Example Using R. Chapman \& Hall/CRC Computer Science \& Data Analysis

International Agency for Research on Cancer (2017) Monographs on the evaluation of carcinogenic risks to humans. 2017. Lyon: WHO.

Kauppinen T, Toikkanen J, Pedersen D, Young R, Ahrens W, Boffetta P, Hansen J, Kromhout H, Maqueda Blasco J, Mirabelli D, de la Orden-Rivera V, Pannett B, Plato N, Savela A, Vincent R, Kogevinas M. (2000) Occupational exposure to carcinogens in the European Union. Occup Environ Med; 57:10-8.

Kennedy SM, Koehoorn M. (2003) Exposure assessment in epidemiology: does gender matter? Am J Ind Med; 44:576-583.

Lanna F. (2013) Du travailleur au malade : retour sur la reconstitution du parcours professionnel de patients atteints de cancer en Seine-Saint-Denis. La nouvelle revue du travail; 2. https://nrt.revues.org/653 (Accessed June 23, 2017)

Lebart L, Morineau A, Piron M. (2000) Statistique Exploratoire Multidimensionnelle. Paris: Dunod.

Marchand A. (2016) Quand les cancers du travail échappent à la reconnaissance. Sociétés Contemporaines; 102:103-128.

Martın MA. (2000) On the role of Shannon’s entropy as a measure of heterogeneity. Geoderma; $98: 1-3$.

Messing K. (1998) One-Eyed Science: Occupational Health and Working Women. Philadelphia: Temple University Press.

Momoli F, Abrahamowicz M, Parent M-É, Krewski D, Siemiatycki J. (2010) Analysis of Multiple Exposures: An Empirical Comparison of results From Conventional and Semi-Bayes Modeling Strategies. Epidemiology; 21:144-51.

Niedhammer I, Chastang J-F, David S, Kelleher C. (2008) The contribution of occupational factors to social inequalities in health: findings from the national French SUMER survey. Soc Sci Med; 67:1870-81.

Papathomas M, Molitor J, Richardson S, Riboli E, Vineis P. (2011) Examining the Joint Effect of Multiple Risk Factors Using Exposure Risk Profiles: Lung Cancer in Nonsmokers. Environ Health Perspect; 119:84-91. 
Peters CE, Ge CB, Hall AL, Davies HW, Demers, PA (2015) CAREX Canada: an enhanced model for assessing occupational carcinogen exposure. Occup Environ Med; 72:64-71.

Quinn MM. (2011) Why do women and men have different occupational exposures? Occup Environ Med; 68:861-2.

RESEAU SCOP93 (2005) Occupational Cancer in a Paris Suburb: First Results of a Proactive Research Study in Seine Saint-Denis. Int J Occup Environ Health; 11:263-275.

Siemiatycki J, Richardson L, Straif K, Latreille B, Lakhani R, Campbell S, Rousseau MC, Boffetta P. (2004) Listing occupational carcinogens. Environ Health Perspect; 112:1447-59.

Straif K. (2012) Estimating the burden of occupational cancer as a strategic step to prevention. Br J Cancer; 107 Suppl:S1-2.

Takala J. (2015) Eliminating occupational cancer. Ind Health; 53:307-9.

Thébaud-Mony A. (2006) Histoires professionnelles et cancer. Actes Rech Sci Soc; 163:18-31.

Thébaud-Mony A, Daubas-Letourneux V, Jean A. (2009) Exposition professionnelle aux cancérogènes et parcours professionnels. Post-enquête SUMER 2003. Paris: DARES.

Vogel L. (2003) La santé des femmes au travail en Europe : des inégalités non reconnues. Bruxelles : ETUI. ISBN 2-930003-48-0.

Walker NJ, Crockett PW, Nyska A, Brix AE, Jokinen MP, Sells DM, et al. (2004) Dose-Additive Carcinogenicity of a Defined Mixture of "Dioxin-like Compounds.” Environ. Health Perspect; 113:43-8.

Wild CP. (2005) Complementing the genome with an "exposome”: the outstanding challenge of environmental exposure measurement in molecular epidemiology. Cancer Epidemiol Biomarkers Prev; 14:1847-50. 
Table 1: Characteristics of participants included in the study $(n=1017)$ by gender, the GISCOP cohort, Seine-Saint-Denis, France, 20022010.

\begin{tabular}{|c|c|c|c|c|c|c|c|}
\hline & \multicolumn{3}{|c|}{ Men $(n=834)$} & \multicolumn{3}{|c|}{ Women $(n=183)$} & \multirow{2}{*}{ p-value } \\
\hline & $\mathbf{n}$ & $\%$ & Mean (min-max) & $\mathbf{n}$ & $\%$ & Mean (min-max) & \\
\hline Age at diagnosis & & & & & & & $\mathrm{p}=0.002^{\mathrm{a}}$ \\
\hline$<50 \mathrm{y} / \mathrm{o}$ & 76 & 9.11 & & 33 & 18.03 & & \\
\hline$\geq 50 \&<65 \mathrm{y} / \mathrm{o}$ & 381 & 45.68 & & 84 & 45.90 & & \\
\hline$\geq 65 \mathrm{y} / \mathrm{o}$ & 377 & 45.20 & & 66 & 36.07 & & \\
\hline Type of cancer & & & & & & & $\mathrm{p}=0.20^{\mathrm{a}}$ \\
\hline Respiratory $^{\mathrm{c}}$ & 784 & 94.00 & & 173 & 94.54 & & \\
\hline Urinary $^{\mathrm{d}}$ & 35 & 4.20 & & 4 & 2.19 & & \\
\hline Hematological $^{\mathrm{e}}$ & 15 & 1.80 & & 6 & 3.28 & & \\
\hline Metastasis at diagnosis & & & & & & & $\mathrm{p}=0.96^{\mathrm{a}}$ \\
\hline Yes & 381 & 45.68 & & 82 & 44.81 & & \\
\hline No & 352 & 42.21 & & 78 & 42.62 & & \\
\hline Unknown & 101 & 12.11 & & 23 & 12.57 & & \\
\hline Period at career start & & & & & & & $\mathrm{p}<0.001^{\mathrm{a}}$ \\
\hline$<1950$ & 201 & 24.10 & & 32 & 17.49 & & \\
\hline Between 1950 and 1959 & 239 & 28.66 & & 38 & 20.77 & & \\
\hline Between 1960 and 1969 & 248 & 29.74 & & 49 & 26.78 & & \\
\hline$\geq 1970$ & 146 & 17.51 & & 64 & 34.97 & & \\
\hline Main industry sector & & & & & & & $\mathrm{p}<0.001^{\mathrm{a}}$ \\
\hline Agriculture, fishing & 10 & 1.20 & & 2 & 1.09 & & \\
\hline Construction & 199 & 23.86 & & 4 & 2.19 & & \\
\hline Services & 321 & 38.49 & & 121 & 66.12 & & \\
\hline Manufacturing and extractive industry & 304 & 36.45 & & 56 & 30.60 & & \\
\hline Number of jobs held & & & $6.25(1-32)$ & & & $4.87(1-37)$ & $\mathrm{p}<0.001^{\mathrm{b}}$ \\
\hline Number of occupational carcinogens & & & $3.64(0-12)$ & & & $1.36(0-7)$ & $\mathrm{p}<0.001^{\mathrm{b}}$ \\
\hline
\end{tabular}


${ }^{a}$ Fisher exact test comparing characteristics according to gender

b Student test comparing characteristics according to gender

c International Classification of Diseases and Related Health Problems, $10^{\text {th }}$ revision: code C30 to C39, C12, C45 to C49

dinternational Classification of Diseases and Related Health Problems, $10^{\text {th }}$ revision: C64-C68

${ }^{\mathrm{e}}$ International Classification of Diseases and Related Health Problems, $10^{\text {th }}$ revision: C81 to C96, D45-D46 
Table 2: Jobs' characteristics (n=6087) by gender, the GISCOP cohort, Seine-Saint-Denis, France, 2002-2010.

\begin{tabular}{|c|c|c|c|c|c|}
\hline & \multicolumn{2}{|c|}{ Men (n=5202) } & \multicolumn{2}{|c|}{ Women $(\mathbf{n}=\mathbf{8 8 5})$} & \multirow{2}{*}{ p-value ${ }^{a}$} \\
\hline & $\mathbf{N}$ & $\%$ & $\mathbf{N}$ & $\%$ & \\
\hline Industry sector & & & & & $\mathbf{p}<0.001$ \\
\hline Agriculture, fishing and forestry & 128 & 2.5 & 11 & 1.2 & \\
\hline Construction & 1243 & 23.9 & 14 & 1.6 & \\
\hline Services & 1116 & 21.5 & 408 & 46.1 & \\
\hline $\begin{array}{l}\text { Manufacturing and extractive } \\
\text { industry }\end{array}$ & 2715 & 52.2 & 452 & 51.1 & \\
\hline Occupational category & & & & & $\mathrm{p}<0.001$ \\
\hline Professionals and managers & 124 & 2.4 & 27 & 3.1 & \\
\hline Associates professionals & 227 & 4.4 & 70 & 7.9 & \\
\hline $\begin{array}{l}\text { Services, sales and administration } \\
\text { workers }\end{array}$ & 557 & 10.7 & 475 & 53.7 & \\
\hline Technicians & 319 & 6.1 & 8 & 0.9 & \\
\hline $\begin{array}{l}\text { Agricultural, Fish and forestry } \\
\text { workers }\end{array}$ & 135 & 2.6 & 11 & 1.2 & \\
\hline $\begin{array}{l}\text { Drivers, transport. supply chain } \\
\text { workers }\end{array}$ & 488 & 9.4 & 9 & 1.0 & \\
\hline Construction workers & 1263 & 24.3 & 4 & 0.5 & \\
\hline $\begin{array}{l}\text { Electrical and Electronic trades } \\
\text { workers }\end{array}$ & 163 & 3.1 & 11 & 1.2 & \\
\hline $\begin{array}{l}\text { Wood, confection and printing } \\
\text { workers }\end{array}$ & 219 & 4.2 & 54 & 6.1 & \\
\hline Metal, mechanical workers & 988 & 19 & 46 & 5.2 & \\
\hline Industrial processing workers & 207 & 4.0 & 77 & 8.7 & \\
\hline Other workers ${ }^{\mathrm{b}}$ & 267 & 5.1 & 92 & 10.4 & \\
\hline Army & 245 & 4.7 & 1 & 0.1 & \\
\hline Period at job start & & & & & $\mathrm{p}<0.001$ \\
\hline$<1950$ & 396 & 7.6 & 60 & 6.8 & \\
\hline$\geq 1950 \&<1970$ & 2237 & 43 & 257 & 29.0 & \\
\hline
\end{tabular}




\begin{tabular}{|c|c|c|c|c|c|}
\hline$\geq 1970 \&<1996$ & 2282 & 43.9 & 499 & 56.4 & \\
\hline$\geq 1997$ & 287 & 5.5 & 69 & 7.8 & \\
\hline Age at job start & & & & & 0.014 \\
\hline$<20$ y/o & 1498 & 28.8 & 293 & 33.1 & \\
\hline$\geq 20 \&<30 \mathrm{y} / \mathrm{o}$ & 1818 & 34.9 & 317 & 35.8 & \\
\hline$\geq 30 \&<45 \mathrm{y} / \mathrm{o}$ & 1377 & 26.5 & 203 & 22.9 & \\
\hline$\geq 45 \mathrm{y} / \mathrm{o}$ & 509 & 9.8 & 72 & 8.1 & \\
\hline Occupational segregation ${ }^{c}$ & & & & & $\mathbf{p}<\mathbf{0 . 0 0 1}$ \\
\hline Men-dominated occupations & 3282 & 63.1 & 91 & 10.3 & \\
\hline Mixed occupations & 1164 & 22.4 & 274 & 31.0 & \\
\hline Women-dominated occupations & 756 & 14.5 & 520 & 58.7 & \\
\hline
\end{tabular}

a Fisher exact test comparing jobs' characteristics according to gender

${ }^{\mathrm{b}}$ Other workers category include workers in butchery, bakery, as kitchen assistants; cleaners and other workers whose jobs were not clearly identified.

${ }^{\mathrm{c}}$ As of 1983: men-dominated occupations: < 26,7\% of women in the occupation; women-dominated occupations: > 56,7\% of women; mixed occupations: between 26,7 and $56,7 \%$ of women. 
Table 3: Proportion of OCE and MOCE among jobs by gender and jobs' characteristics (n=6087), the GISCOP cohort, Seine-SaintDenis, France, 2002-2010.

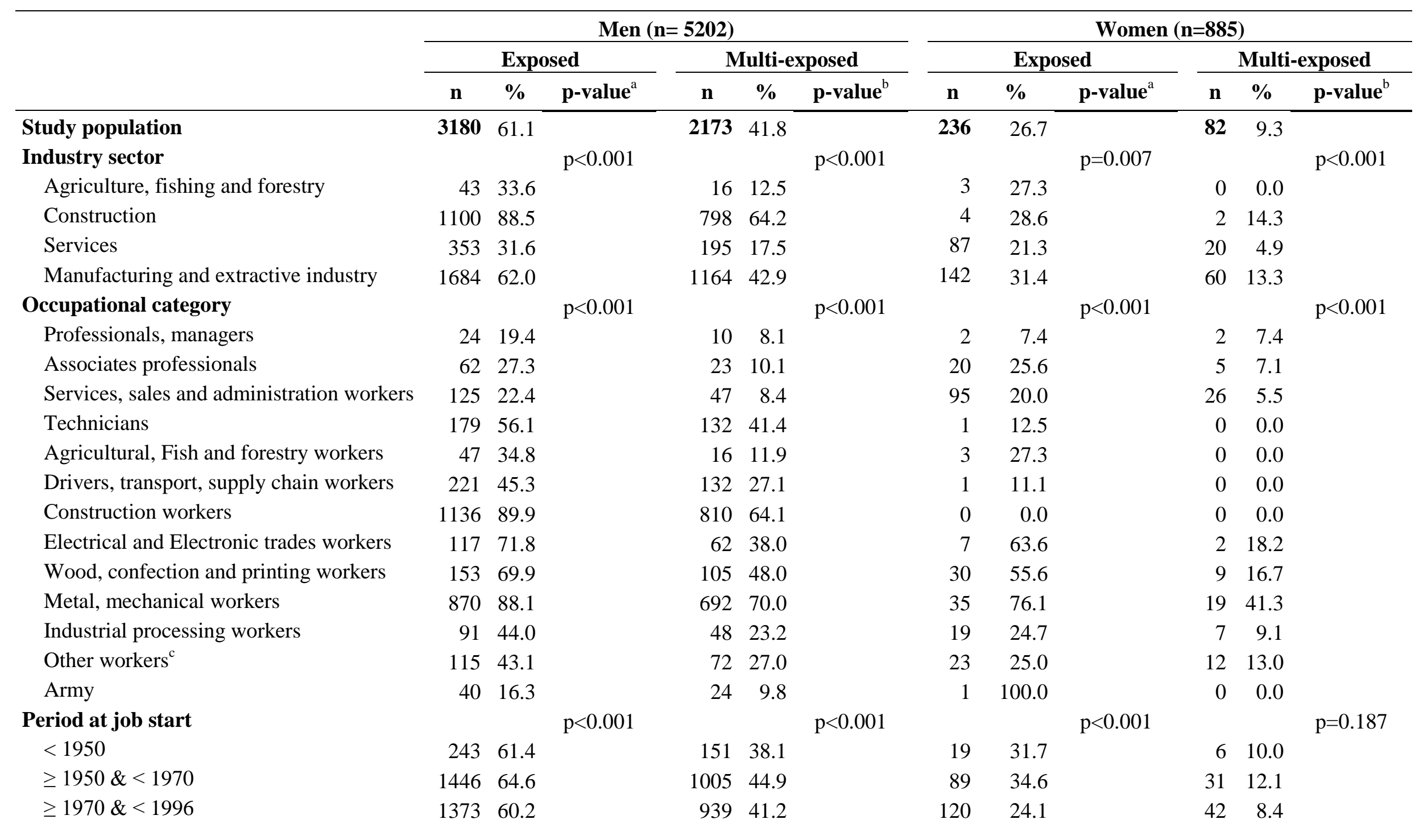




$$
\geq 1997
$$

Age at job start

$$
<20 \mathrm{y} / \mathrm{o}
$$$$
\geq 20 \&<30 \mathrm{y} / \mathrm{o}
$$$$
\geq 30 \&<45 \mathrm{y} / \mathrm{o}
$$$$
\geq 45 \mathrm{y} / \mathrm{o}
$$

\section{Occupational segregation ${ }^{\mathrm{c}}$}

\section{Men-dominated occupations}

Mixed occupations

Women-dominated occupations
$118 \quad 41.1$

$\mathrm{p}<0.001$

$903 \quad 60.3$

$1140 \quad 62.7$

$\begin{array}{ll}882 & 64.1\end{array}$

$255 \quad 50.1$

$\mathrm{p}<0.001$

$2473 \quad 75.4$

$\begin{array}{ll}540 & 46.4\end{array}$

$167 \quad 22.1$
$78 \quad 27.2$

$$
\mathrm{p}<0.001
$$

$\begin{array}{ll}630 & 42.1\end{array}$

\begin{tabular}{ll}
$752 \quad 41.4$ \\
\hline
\end{tabular}

$628 \quad 45.6$

$163 \quad 32.0$

$\begin{array}{rrr} & & \mathrm{p}<0.001 \\ 1800 & 54.8 & \\ 309 & 26.6 & \\ 64 & 8.5 & \end{array}$

$3 \quad 4.4$

$$
p=0.174
$$

$\begin{array}{ll}30 & 10.2\end{array}$

$33 \quad 10.4$

$\begin{array}{ll}17 & 8.4\end{array}$

$2 \quad 2.8$

$\mathrm{p}<0.001$

$22 \quad 24.2$

$\begin{array}{ll}30 & 11.0\end{array}$

$30 \quad 5.8$

Fisher exact test comparing exposed vs. non-exposed jobs.

${ }^{\mathrm{b}}$ Fisher exact test comparing multi-exposed jobs ( $\geq 2$ occupational carcinogenic exposures) vs. non-multi-exposed jobs $(\leq 1$ occupational carcinogenic exposure)

c Other workers category include workers in butchery, bakery, as kitchen assistants; cleaners and other workers whose jobs were not clearly identified

${ }^{\mathrm{d}}$ As of 1983: men-dominated occupations: < 26,7\% of women in the occupation; women-dominated occupations: > 56,7\% of women; mixed occupations: between 26,7 and $56,7 \%$ of women. 
Table 4: Description of men and women's patterns of multiple occupational carcinogenic exposures, the GISCOP cohort, Seine-SaintDenis, France, 2002-2010.

\begin{tabular}{|c|c|c|c|c|c|}
\hline Patterns & $\mathbf{N}$ & $\%$ & $\begin{array}{l}\text { Median }^{\mathrm{a}} \\
(\min -\mathrm{max})\end{array}$ & $\begin{array}{l}\text { Occupational } \\
\text { diversity } \\
\text { index }^{\mathrm{b}}\end{array}$ & Main carcinogenic agents ${ }^{c}$ \\
\hline \multicolumn{6}{|l|}{ Among men's jobs $(n=2173)$} \\
\hline Widespread carcinogens & 548 & 25.2 & $3(2-8)$ & 0.60 & $\begin{array}{l}\text { welding fumes, asbestos, lead, diesel exhausts, HAH, PAH and iron } \\
\text { mines }\end{array}$ \\
\hline Mixed silica dust & 401 & 18.5 & $3(2-7)$ & 0.37 & as silica dust, asbestos, bitumen and PAH \\
\hline Heavy metals and combustion products & 64 & 2.9 & $6(2-8)$ & 0.17 & $\begin{array}{l}\text { cobalt, nickel, cadmium, chromium, lead, welding fumes, PAH, } \\
\text { inorganics acids and irons mines }\end{array}$ \\
\hline Organic compounds and radiation & 90 & 4.1 & $3(3-8)$ & 0.27 & $\begin{array}{l}\text { mineral and aqueous oil, ionizing radiation, styrene, acrylonitrile, } \\
\text { acrylamide, composites materials, refractory ceramics fibers, } \\
\text { radionucleotides, acetamide and butadiene }\end{array}$ \\
\hline Metal working & 532 & 24.5 & $3(2-6)$ & 0.61 & chlorinated solvents, metal dust, cutting oil, beryllium, PAH and amines \\
\hline Solvent and painting related compounds & 139 & 6.4 & $4(2-7)$ & 0.30 & $\begin{array}{l}\text { chromium, inorganic acids, lead, benzene pure, developing bath, } \\
\text { cadmium, hydrazine, silica dust, arsenic and chlorinated solvents }\end{array}$ \\
\hline Wood dust, formaldehyde, pesticides & 226 & 10.4 & $3(2-7)$ & 0.42 & $\begin{array}{l}\text { wood dust, formaldehyde, pesticides, nitrosamines, arsenic, mycotoxins, } \\
\text { Methyl Chloride }\end{array}$ \\
\hline Fuels exhausts & 173 & 8 & $2(2-6)$ & 0.31 & Gasoline and diesel fuel exhausts \\
\hline \multicolumn{6}{|l|}{ Among women's jobs $(n=82)$} \\
\hline Biological and organic compounds & 48 & 58.5 & $2(2-4)$ & 0.49 & $\begin{array}{l}\text { passive smoking, formaldehyde, amines, benzene and biological } \\
\text { compounds } \\
\text { metal dust, chlorinated solvents, PAH, inorganic acids, welding fumes, } \\
\text { cutting oil, silica dust mineral oil, nickel, asbestos, developing bath, } \\
\text { cobalt, chromium }\end{array}$ \\
\hline Fuel exhausts & 8 & 9.8 & $2(2-3)$ & 0.15 & Gasoline and diesel fuel exhausts \\
\hline
\end{tabular}

${ }^{a}$ median (min-max) number of occupational carcinogenic exposures observed on jobs by pattern.

b estimated using Shannon entropy (see methods section for formula and interpretation).

'carcinogens are presented by descending v-test [See supplementary Table 2 and 3], (i.e. the higher v-test the most representative are the carcinogens to a specific pattern 


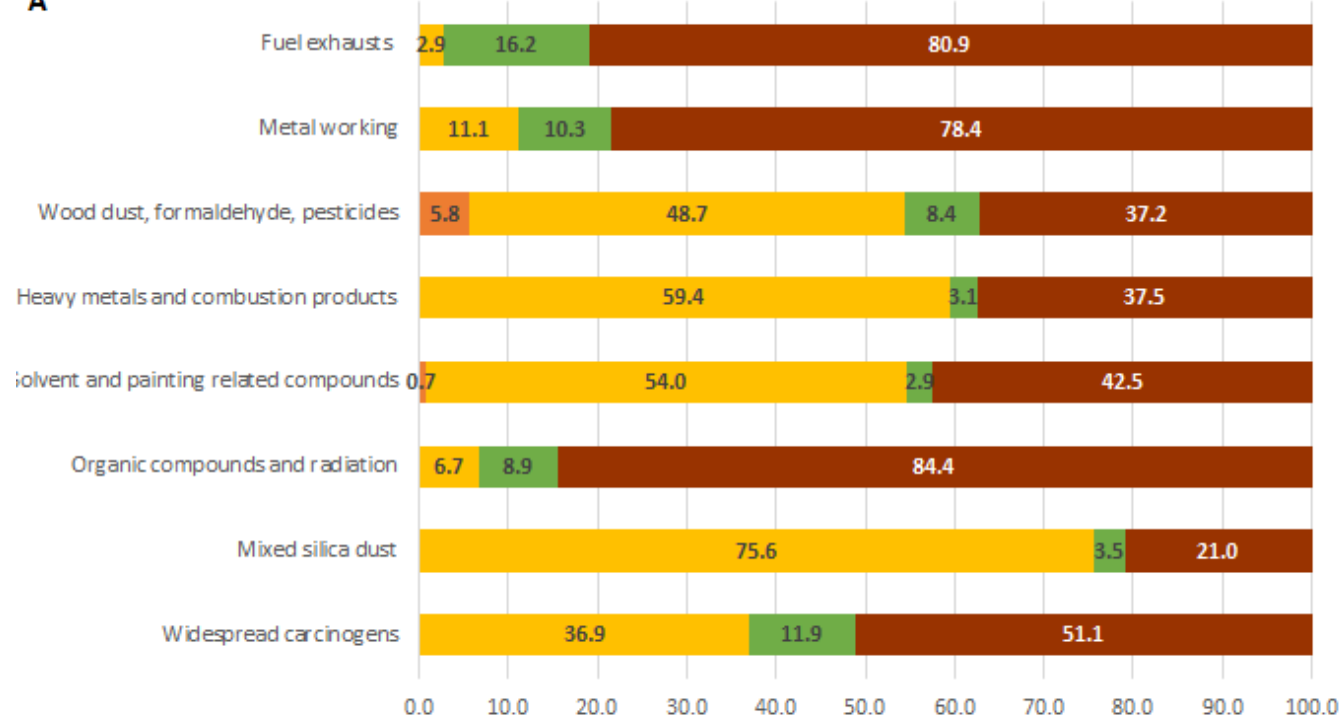

B

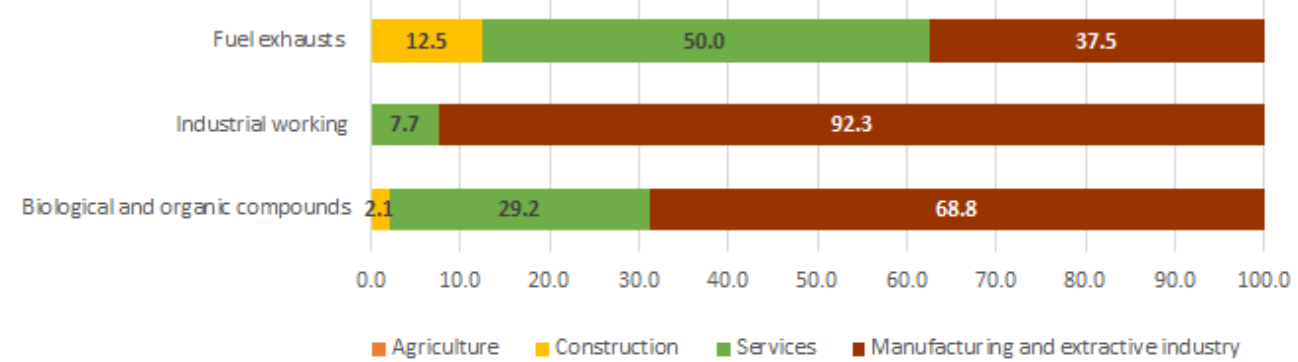

Figure 1. Industry sectors' distribution among men's MOCE patterns (A) and women's MOCE patterns (B). 
A
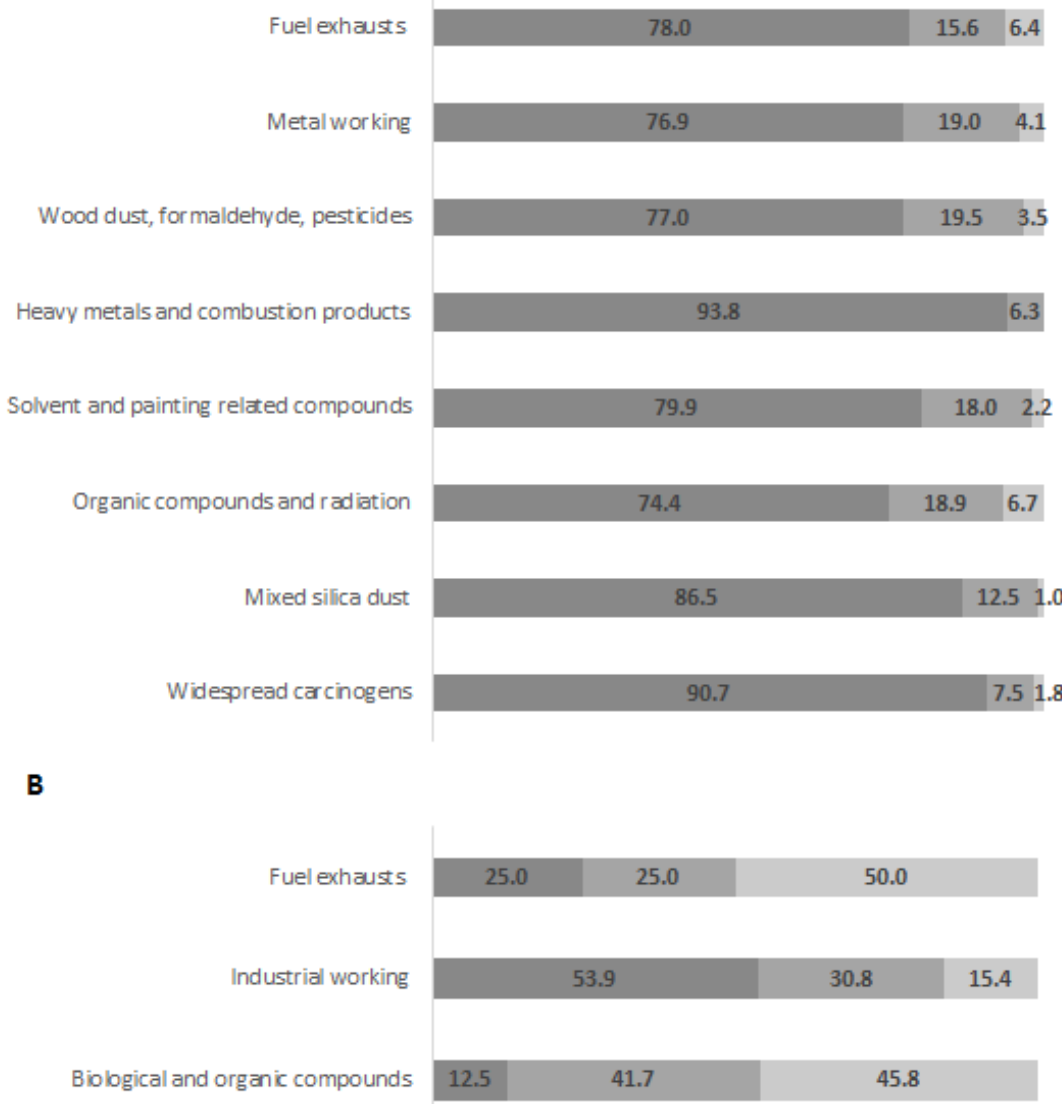

$\begin{array}{llllllllllll}0 & 10 \% & 20 \% & 30 \% & 40 \% & 50 \% & 60 \% & 70 \% & 80 \% & 90 \% & 100 \%\end{array}$

- Men-dominated occupations =Mixed occupations |women-dominated occupations

Figure 2. Distribution of occupational segregation among men's MOCE patterns (A) and women's MOCE patterns (B). 